\title{
Uma nova espécie de Barbiellinia (Diptera, Stratiomyidae) do Rio de Janeiro
}

\author{
José Roberto Pujol-Luz \& \&abio Siqueira P. Godoi ${ }^{2}$
}

1. Departamento de Zoologia, Instituto de Ciências Biológicas, Universidade de Brasília, 70910-900 Brasília, DF, Brasil. (jrpujol@unb.br) 2. Departamento de Biologia, Universidade Federal do Amazonas, Av. General Rodrigo Otávio Jordão Ramos, 3000, 69077-000 Manaus, AM, Brasil. (fgodoi@gmail.com)

\begin{abstract}
A new species of Barbiellinia (Diptera, Stratiomyidae) from Rio de Janeiro, Brazil. The genus Barbiellinia Bezzi, 1922, with five species, is endemic from Brazil. Here we described a new species Barbiellinia illaetabilis sp. nov. based on 26 specimens (25 males and 1 female) from the State of Rio de Janeiro, Brazil.
\end{abstract}

KEYWORDS. Lower Brachycera, Chiromyzinae, taxonomy, Brazil.

RESUMO. O gênero Barbiellinia Bezzi, 1922 possui cinco espécies endêmicas do Brasil. Neste trabalho descrevemos uma nova espécie Barbiellinia illaetabilis sp. nov. com base em 26 espécimes (25 machos e 1 fêmea) do estado do Rio de Janeiro, Brasil.

PALAVRAS-CHAVES. Brachycera inferiores, Chiromyzinae, taxonomia, Brasil.

Os Stratiomyidae são dípteros Brachycera da Infraordem Stratiomyomorpha e encontram-se amplamente distribuídos por todas as regiões zoogeográficas, sendo a Neotrópica a de maior riqueza de espécies onde estão registradas 987 das 2.651 espécies conhecidas (WoOdLEY, 2001). As doze subfamílias reconhecidas ocorrem na região Neotropical: Parhadrestriinae, Chiromyzinae, Beridinae, Antissinae, Pachygastrinae, Clitellariinae, Hermetiinae, Chrysochlorininae, Sarginae, Raphiocerinae, Stratiomyinae, Nemotelinae, e apenas Parhadrestriinae não possui registro no Brasil (WoodLEy, 2001).

Os Chiromyzinae foram reconhecidos por WoOdLEY (2001) como um grupo monofilético por causa da redução das peças bucais dos adultos. Suas larvas são as únicas que possuem um aparelho bucal mastigador, com mandíbulas bem desenvolvidas ao invés do sistema mandibulo-maxilar e corpo formado por 12 segmentos ao invés de 11 segmentos como as demais larvas conhecidas de Stratiomyidae (Pujol-Luz \& Vieira, 2000). São reconhecidos 14 gêneros e 56 espécies com distribuição nas regiões Neotropical (34 espécies); Australásica (22 espécies) e Neártica (uma espécie introduzida). Na Região Neotropical ocorrem nove gêneros (WoODLEY, 2001).

Descrições pouco precisas e raramente utilizando os dois sexos, além da carência quase total de ilustrações caracterizaram os primeiros estudos das espécies neotropicais de Chiromyzinae (HARDY, 1920; ENDERLEIN, 1921; BEZZI, 1922; AlBERTIN, 1930; LindNER, 1943; JAMES, 1975), tornando difícil a tarefa de identificação das suas espécies e estudos mais avançados sobre filogenia.

Estudos mais recentes sobre as espécies de Chiromyzinae neotropicais destacaram especialmente a morfologia das espermatecas e trataram de revisões ou redescrições das espécies de Barbiellinia Bezzi, 1922; Chiromyza Wiedemann, 1820; Hylorops Enderlein, 1921; Mapuchemyia Woodley, 2001 (=Hylorus Philippi, 1865, pré-ocupado por Thompson, 1864); Mesomyza Enderlein,
1921 e Nonacris Walker, 1850 (Pujol-Luz \& Oliveira, 1999; Oliveira \& Pujol-Luz, 2000a, b ,c; Pujol-Luz et al., 2001; WOODLEY, 2001).

Barbiellinia é endêmico do Brasil e difere dos demais gêneros neotropicais por apresentar tamanho variável e aspecto bastante frágil, coloração geralmente castanho-claro, abdômen longo e pouco esclerotizado; corpo, pernas e asas com densa pilosidade e os machos com olhos dicópticos e pilosos. A espécie-tipo Barbiellinia hirta Bezzi, 1922 foi descrita com base em um único exemplar macho de Termas de Lindóia, estado de São Paulo (BEzZI, 1922). JAMES (1973) incluiu no gênero Barbiellinia quatro espécies de Chiromyza, todas descritas por ENDERLEIN (1921): B. annulipes, B. lineata, $B$. murcicornis e B. parvicornis. As cinco espécies foram reconhecidas como válidas no catálogo de Woodley (2001).

Neste trabalho uma nova espécie de Barbiellinia é descrita, ilustrada e comparada com as demais espécies conhecidas do gênero.

\section{MATERIAL E MÉTODOS}

Foram examinados 26 espécimes ( 25 machos e uma fêmea) provenientes da coleção entomológica do Museu Nacional da Universidade Federal do Rio de Janeiro (MNRJ) que estavam identificados apenas no nível do gênero (Barbiellinia). O material foi comparado com as seguintes espécies, $B$. hirta, $B$. annulipes, $B$. lineata, $B$. murcicornis e $B$. parvicornis e suas descrições originais encontradas em ENDERLEIN (1921) e BEZZI (1922). As terminálias dos machos foram dissecadas e fervidas em ácido lático para clarificação e análise, posteriormente foram incluídas e guardadas em microtubos com glicerina. A terminologia utilizada para os caracteres morfológicos externos segue McAlPINE (1981) e para os caracteres da genitália masculina segue SinclaIR et al. (1994) e 
Woodley (1995). O material-tipo está depositado nas seguintes instituições: MNRJ; Coleção de Invertebrados do Instituto Nacional de Pesquisas da Amazônia (INPA) e Museu de Zoologia da Universidade de São Paulo (MSZP).

\section{Barbiellinia illaetabilis sp. nov.} (Figs. 1-20)

Material-tipo. Holótipo ơ , BRASIL, Rio de Janeiro: Repr.[Represa] Rio Grande, Rio de Janeiro, Brasil / F. M. Oliveira [col.], V.[19]72 (MNRJ). Condição do holótipo: boa, com genitália acondicionada em microtubo contendo glicerina; asa e antena esquerda montada em microlâminas permanentes. Microtubo e microlâminas afixados ao alfinete do espécime. Parátipos: Rio de Janeiro: Repr.[Represa] Rio Grande, Jacarepaguá, Rio [de Janeiro], 2 ठ', VIII.[19]69, M. Alvarenga [col.] (MNRJ); 4 o', 1 क, IX.[19]69 (MNRJ); 5 o, IX.[19]69 (INPA); 9 ơ, X.[19]69 (MNRJ); 4 o , V.[19]72, F. M. Oliveira [col.] (MZSP).

Distribuição geográfica. Brasil (Rio de Janeiro).

Etimologia. Do latim, illaetabilis = melancólico; alusivo à coloração do tegumento de aspecto "pálido".

Macho (Fig. 1). Comprimento total do holótipo: 7,2 $\mathrm{mm}$, excluindo as antenas. Cabeça (Figs. 2-4) subglobosa; olhos dicópticos pilosos e de coloração escura com margem clara. Triângulo ocelar escuro, levemente proeminente, com ocelos grandes e amarelados. Fronte mais longa que larga com calo frontal proeminente e pêlos castanhos e longos; face pilosa. Aparelho bucal vestigial com palpos curtos e uni-segmentados, de coloração amarelada. Antenas (Fig. 5), de coloração castanha, exceto o terceiro flagelômero mais escuro, cerdas longas e escuras. Pedicelo mais longo e largo do que o escapo; flagelo com três flagelômeros, o primeiro tão longo quanto largo e duas vezes mais longo do que o segundo; o segundo, mais largo do que longo e o terceiro mais longo do que largo sendo do mesmo comprimento que o primeiro, gradualmente afinado da base até o ápice e de coloração escura. Tórax (Fig. 6) com coloração geral castanho-claro, com densa pilosidade. Mesonoto com quatro faixas longitudinais: duas centrais inconspícuas, aparentando formar apenas uma mancha central que se estende da porção anterior do mesonoto até a sutura transversal; duas faixas laterais originadas pouco além da margem anterior se estendem ao longo do mesonoto até atingirem o escutelo. Escutelo subtriangular com ápice arredondado, piloso e de coloração castanho-claro com a porção basal média mais escura. Pernas longas, castanhas, com tarsos castanho-escuros. Coxas longas, a posterior mais longa que as demais, a anterior e a média sub-iguais com pilosidade acentuada na porção anterior, exceto na coxa anterior, com pilosidade também na porção posterior. Trocânteres com pilosidade na porção anterior. Fêmures bem desenvolvidos e pilosos. Tíbias pilosas, com extremidade basal estreita alargando até a extremidade apical; tíbias posteriores achatadas lateralmente exibindo uma curvatura acentuada. Tarsos longos, com densa pilosidade; tarsômero I mais longo do que tarsômeros II e III somados; tarsômeros IV e V pequenos e subiguais. Asas (Fig. 7) mais longas (7,9 mm) que o comprimento do corpo, ápice arredondado; membrana translúcida com densa pilosidade; veias $C, R_{1}$ e $R_{4+5}$ e margem inferior recoberta de pêlos mais longos. Veias bem definidas. $\mathrm{R}_{1}$ quase reta, atingindo a margem costal obliquamente; $R_{2+3}$ inconspícua, retilínea atingindo margem costal próximo a $\mathrm{R}_{1} ; \mathrm{R}_{4+5}$ atingindo a margem costal próximo ao ápice da asa; $\mathrm{r}-\mathrm{m}$ presente; célula $\mathrm{dm}$ hexagonal, larga e alongada; m-cu ausente; $M_{1}$ e $M_{2}$ atingindo a margem da asa; $M_{3}$ ausente; $\mathrm{CuA}_{1}$ reta e atinge a margem da asa; $\mathrm{A}_{1}+\mathrm{CuA}_{2}$ presente. Abdômen (Fig. 1) com dez segmentos, longo e largo, com todos os segmentos visíveis e pouco esclerotizados; coloração geral castanho um pouco mais escuro do que o restante do corpo; piloso, com pêlos mais longos na margem lateral. Terminália com cápsula genital formada pelo hipândrio, gonocoxitos e gonóstilos (Fig. 8) grande, mais larga do que longa, com margem anterior truncada e margens laterais arredondadas. Margem posterior do hipândrio subtriangular, longa com o ápice ultrapassando a base de inserção dos gonóstilos e porção posteroventral expandida lateralmente. Gonocoxitos largos e tubulares com as margens laterais arqueadas, apódemas do gonocoxito bem desenvolvidos, convergentes, com a base larga e ápice afilado, ultrapassando a margem anterior da cápsula genital. Gonóstilos longos, largos e convergentes, levemente curvados para dentro; face dorsal com uma acentuada depressão ao longo de toda sua extensão; extremidade basal cilíndrica alargada até o ápice com margem apical média levemente deprimida projetando as margens laterais. Epândrio (Fig. 9) relativamente curto e largo com margens laterais arredondadas; margem anterior com uma forte escavação em forma de "V" e margem posterior levemente arredondada com reentrâncias na porção lateral média. Proctiger subpentagonal (Fig. 9), com as margens arredondadas e ápice estreito e arredondado. Cercos (Fig. 9) alongados não ultrapassando a margem distal do proctiger; porção proximal levemente mais larga do que a porção distal arredondada. Complexo fálico (Figs. 10-12) simples, tubular e longo; extremidade proximal arredondada e sem projeções, duas vezes mais larga do que a extremidade distal em vista ventral; extremidade distal estreita com paredes marcadas por pequenas projeções espiniformes; margem posterior com uma grande abertura longitudinal formada pelo gonóporo bem definido e subtriangular, localizado na face ventral; complexo fálico evidenciando, em vista lateral, leve curvatura dorsal com exceção da porção anterior projetada ventralmente; final da porção mediana e início do $1 / 3$ posterior com um alargamento pronunciado direcionado dorsalmente; extremidade apical afilada, com margem ventral marcada por pequenas projeções espiniformes. Edeágo longo e estreito, com extremidade anterior e parte da posterior exposta. Bomba espermática não evidenciada. Estrutura de acoplamento do complexo fálico em forma de "U" com porção mediana relativamente larga com uma protuberância cônica, projetando anteriormente as extremidades laterais ligadas aos apódemas gonocoxais; a estrutura se liga ao complexo fálico por meio de projeções da porção ventral média, 
longa e estreita, que se estende anteriormente até se ligar à porção apical do complexo fálico.

Fêmea. Comprimento total $14 \mathrm{~mm}$, excluindo as antenas (Fig. 13). Olhos com pouca pilosidade e dicópticos, muito afastados entre si. Triângulo ocelar castanho, proeminente, com ocelos ligeiramente menores e brancos (Fig. 14). Fronte ligeiramente mais larga do que longa, distância entre os olhos quase três vezes maior que a do macho; ausência do calo frontal, mas com uma fissura longitudinal quase atingindo a base das antenas; pilosidade mais esparsa (Figs. 14-16). Antena (Fig. 17) mais longa, com flagelo mais estreito; primeiro flagelômero duas vezes mais longo do que largo e o segundo tão longo quanto largo. Tórax (Fig. 18) com mesonoto maior e mais desenvolvido, com pêlos mais curtos e quatro faixas longitudinais conspícuas e bem definidas. Escutelo (Fig. 18) castanho-escuro com pilosidade curta e esparsa. Pernas (Fig. 13) castanho-escuras, exceto coxas, porção apical e do $1 / 3$ basal dos fêmures, porção apical das tíbias e os $2 / 3$ basais do tarsômero I; tarsômero I muito grande, sendo mais longo do que os tarsômeros II, III e IV somados. Asas (Fig. 19) muito longas e estreitas, com ápice acuminado; todas as veias bem evidentes; veia $\mathrm{C}$ mais estreita e com pêlos mais longos; $\mathrm{R}_{1}$ com poucos pêlos e estes mais longos; $\mathrm{R}_{4+5}$ com pêlos ausentes; célula $\mathrm{dm}$ hexagonal levemente menor; $\mathrm{M}_{1}$ e $\mathrm{M}_{2}$ se originando próximas entre si. Abdômen (Fig. 13) muito grande, cerca de duas vezes mais longo que o do macho, e gradualmente

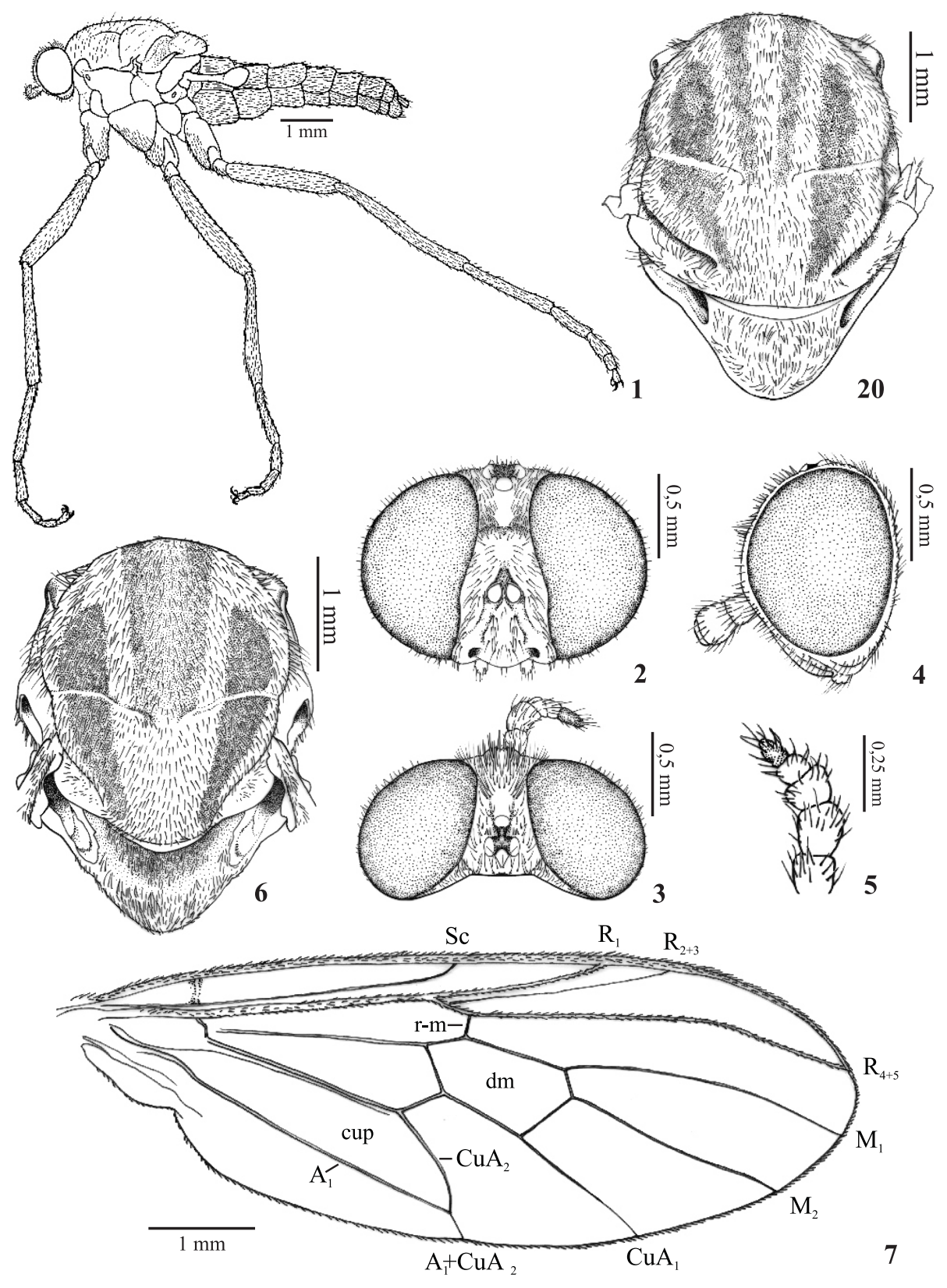

Figuras 1-7, 20. 1-7, Barbiellinia illaetabilis sp. nov. (holótipo $\left.ठ^{7}\right)$. 1, habitus; 2, cabeça, vista frontal; 3, cabeça, vista dorsal; 4, cabeça, vista lateral; 5, antena; 6, tórax, vista dorsal; 7, asa. 20, B. illaetabilis sp. nov. (parátipo $\left.\bigcirc^{7}\right)$ : tórax, vista dorsal. 

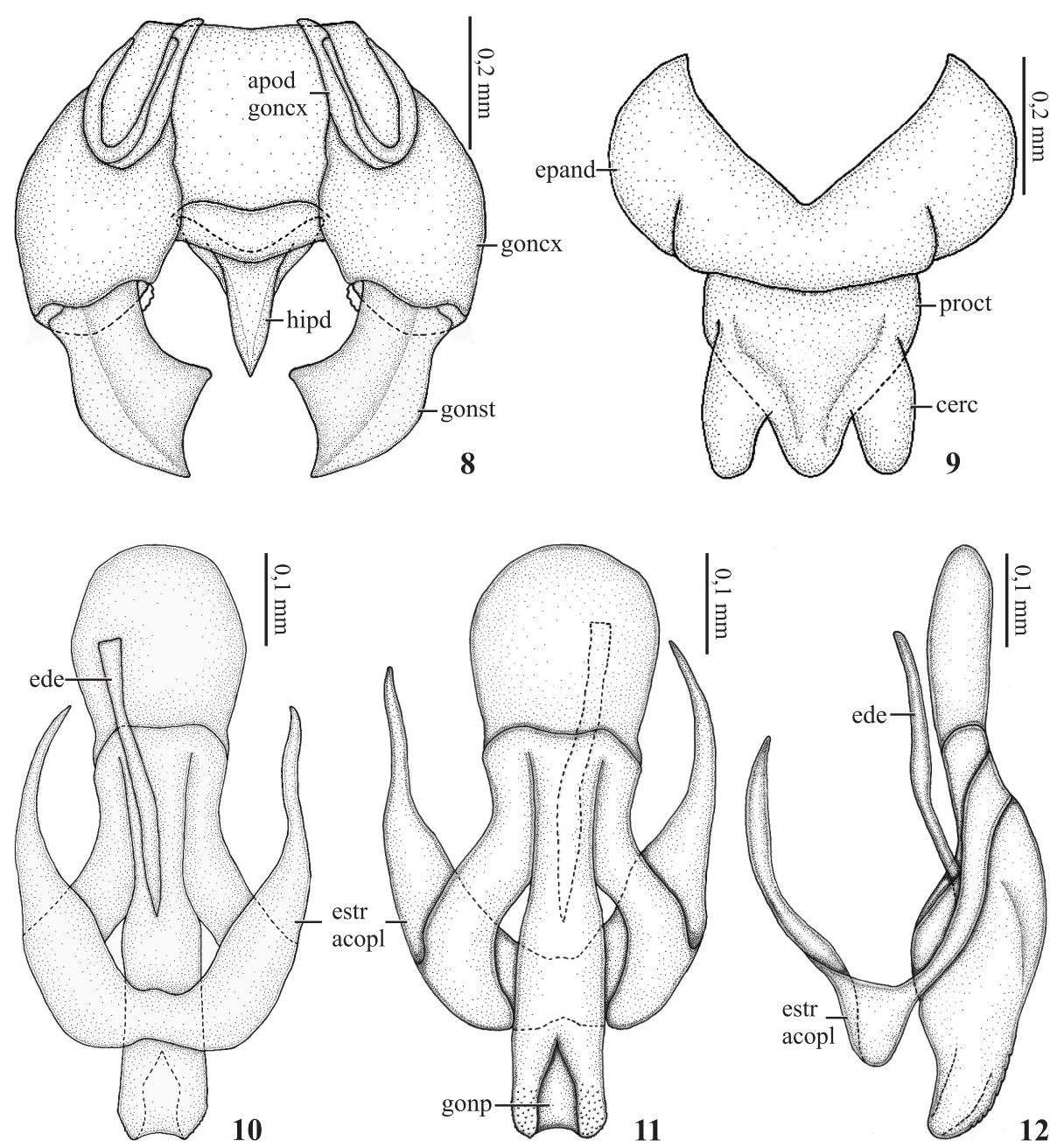

Figuras 8-12. Barbiellinia illaetabilis sp. nov. (holótipo ơ'). 8, cápsula genital (hipândrio, gonocoxitos, apódemas gonocoxais e gonóstilos), vista dorsal; 9, epândrio, proctiger e cercos, vista dorsal; 10, complexo fálico, vista dorsal; 11, complexo fálico, vista ventral; 12 , complexo fálico, vista lateral esquerda (apod goncx, apódema do gonocoxito; ede, edeago; epand, epândrio; estr acopl, estrutura de acoplamento; cerc, cercos; goncx, gonocoxito; gonp, gonóporo; gonst, gonóstilo; hipd, hipândrio; proct, proctiger).

estreitado na forma de um ovipositor com os últimos segmentos escurecidos; pilosidade menos acentuada com ausência de pêlos longos nas laterais.

Variações. Tamanho dos machos de 5,9 a 8,0 $\mathrm{mm}$. Olhos avermelhados, rajados ou escuros com margem clara. Largura da fronte de 0,17 a $0,33 \mathrm{~mm}$. Antena com flagelo castanho como os demais segmentos ou totalmente castanho-escuro. Faixas longitudinais do mesonoto conspícuas ou inconspícuas, com distância variável entre as faixas longitudinais médias (Fig. 20). Ápice do escutelo castanho-escuro. Tíbia posterior normal ou achatada lateralmente. Veias $\mathrm{Sc}$ e $\mathrm{R}_{2+3}$ bem definidas; distância entre a origem das veias $M_{1}$ e $M_{2}$ variável.

Comentários taxonômicos. A espécie-tipo $B$. hirta não foi examinada. O holótipo está em boas condições e depositado no Museo Civico di Storia Naturale em Milão, Itália. No entanto, a descrição original de BEzzI (1922) é suficiente para caracterizar a espécie-tipo demonstrando suas diferenças em relação à nova espécie descrita aqui. Barbiellinia hirta possui a cabeça inteiramente amarelada com a placa ocelar preta; antenas totalmente amareladas e com pilosidade preta; escapo mais curto que o pedicelo; flagelo tão longo quanto o escapo e pedicelos juntos; mesonoto castanho-amarelado com pelos longos e escuros; faixas longitudinais curtas, claras ou inconspícuas, a não ser por uma linha mediana muito clara; escutelo castanho-amarelado; coxas inteiramente amareladas e cobertas por longos pelos pretos; últimos segmentos dos tarsos escurecidos; tíbias amareladas, tíbia I mais delgada que as demais. As genitálias de oito exemplares machos de $B$. hirta da coleção do MNRJ foram examinadas, permitindo apontar as seguintes diferenças: complexo fálico simples, tubular e longo; extremidade proximal arredondada, mais estreita do que a extremidade distal em vista ventral e com uma quilha pronunciada dorsalmente em vista lateral; extremidade distal com paredes marcadas por pequenas projeções espiniformes; edeágo longo e estreito; estrutura de acoplamento do complexo fálico em forma de "U" com porção mediana com curvatura suave projetando anteriormente as extremidades laterais. 

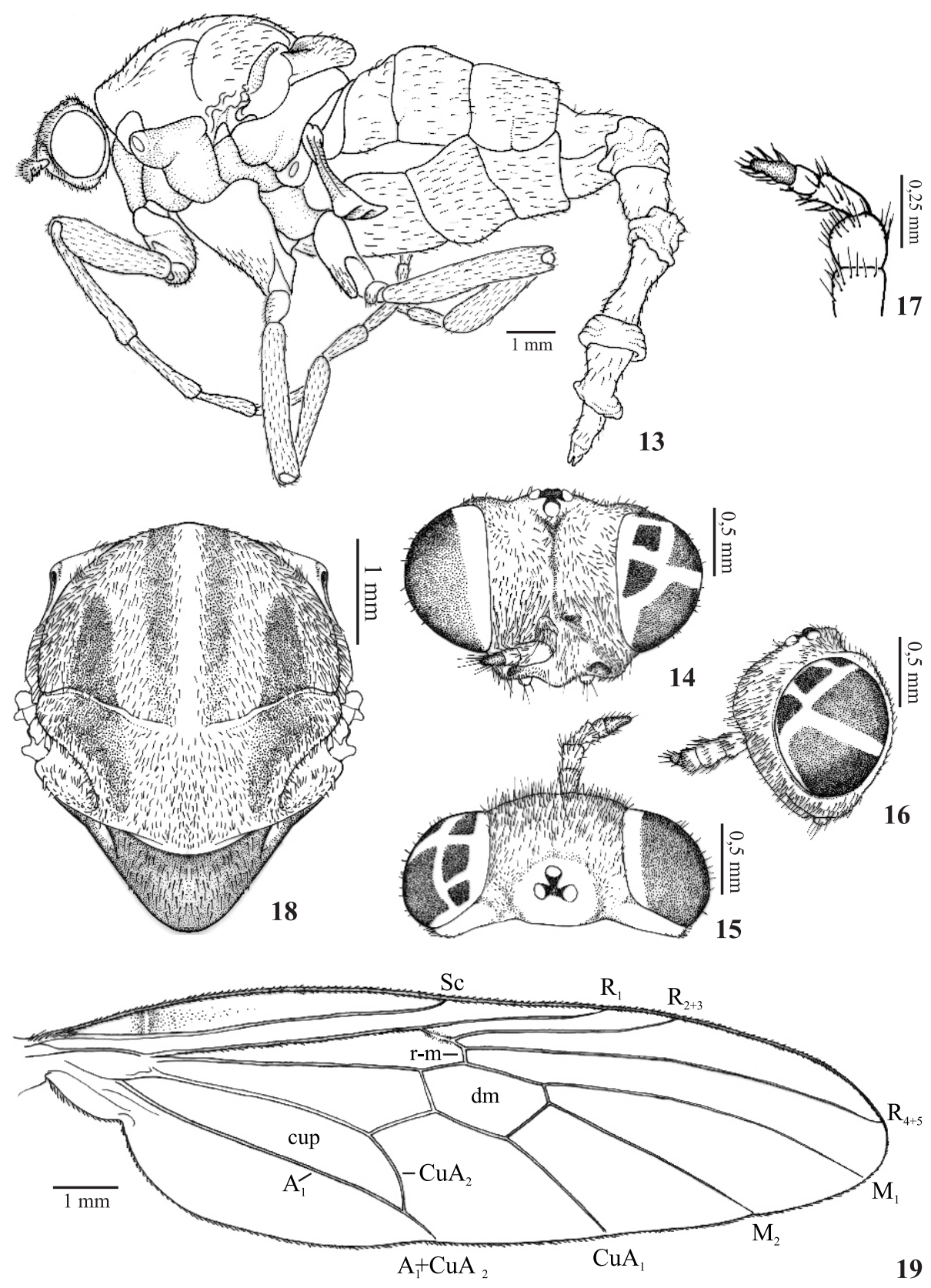

Figuras 13-19. Barbiellinia illaetabilis sp. nov. (parátipo fêmea +). 13, habitus; 14, cabeça, vista frontal; 15, cabeça, vista dorsal; 16 , cabeça, vista lateral; 17, antena; 18, tórax, vista dorsal; 19, asa.

Agradecimentos. Ao Conselho Nacional de Desenvolvimento Científico e Tecnológico-CNPq, processo 308636/2007-4 (JRPL) e 130670/2004-9 (FSPG). Aos colegas José Albertino Rafael e Juliana de Souza Araújo pela revisão do manuscrito.

\section{REFERÊNCIAS BIBLIOGRÁFICAS}

Albertin, D. 1930. Stratiomyidae in British Museum (Natural History). Diptera of Patagonia and South Chile 5(2):93-105.

Bezzi, M. 1922. On the South American species of the dipterous genus Chiromyza Wied. Annals Entomological Society of America 15(2):117-124.

ENDERLEIN, G. 1921. Über die phyletisch älteren Stratiomyiidensubfamilien (Xylophaginae, Chiromyzinae, Solvinae, Beridinae, und Coenomyiinae). Mitteilungen aus dem Zoologischen Museum in Berlin 10(1):151-214.
Hardy, G. H. 1920. A revision of the Chiromyzini (Diptera). Proceedings of the Linnaean Society of New South Wales 45(4):532-542.

James, M. T. 1973. Family Stratiomyidae. In: Papavero, N. ed. A Catalogue of the Diptera of Americas South of the United States. São Paulo, Departamento de Zoologia, Secretaria de Agricultura. v.26, p.1-95.

1975. A preliminary review of the Stratiomyidae of Chile Melanderia 20:1-28.

LindNER, E. 1943. Südchilenische Stratiomyiiden (Dipt.). Annalen des Naturhistorischen Museums in Wien 53(2):89-100.

McAlpine, J. F. 1981. Morphology and terminology-adults. In: McAlpine, J. F.; Peterson, B. V.; Shewell, G. E.; Teskey, H. J.; Vockeroth, J. R. \& Wood, D. M. eds. Manual of Neartic Diptera. Otawa, Research Branch, Agriculture Canada. v.1. monograph 27, p.9-63.

Oliveira, A. C. D. \& Pujol-Luz, J. R. 2000a. Revisão do gênero 
Hylorus Philippi (Diptera, Stratiomyidae). Contribuições Avulsas sobre a História Natural do Brasil, Série Zoologia 12:1-10.

2000b. Morfologia das espermatecas de Hylorops phillipii Enderlein (Diptera, Stratiomyidae). Contribuições Avulsas sobre a História Natural do Brasil, Série Zoologia 18:1-5. 2000c. Redescrição de Mesomyza interrupta Enderlein com um estudo sobre as genitálias masculina e feminina (Diptera, Stratiomyidae). Contribuições Avulsas sobre a História Natural do Brasil, Série Zoologia 22:1-7.

Pujol-Luz, J. R. \& Oliveira, A. C. D. 1999. Morfologia das espermatecas de Barbiellinia Bezzi e Chiromyza Wiedemann (Diptera, Stratiomyidae). Contribuições Avulsas sobre a História Natural do Brasil, Série Zoologia 6:1-4.

Pujol-Luz, J. R. \& Vieira, F. D. 2000. A larva de Chiromyza vittata Wiedemann (Diptera, Stratiomyidae). Anais da Sociedade Entomológica do Brasil 29(1):49-55.

Pujol-Luz, J. R.; Oliveira, A. C. D. \& Ururahy-Rodrigues, A. 2001. Morfologia das espermatecas de Nonacris chilensis Lindner, 1943 (Diptera, Stratiomyidae). Contribuições Avulsas sobre a História Natural do Brasil, Série Zoologia 35:1-6.

Sinclair, B. J.; Cumming, J. M. \& Wood, D. M. 1994. Homology and phylogenetic implications of male genitalia in Diptera-Lower Brachycera. Entomologica Scandinavica 24(4):407-432.

Woodley, N. E. 1995. The genera of Beridinae (Diptera: Stratiomyidae). Memoirs of the Entomological Society of Washington 16:1-231.

2001. A World catalog of the Stratiomyidae (Insecta: Diptera). Myia 11:1-475 